\title{
EFFECT OF CALCIUM CHLORIDE TREATMENT BY VACUUM INFILTRATION METHOD ON TEXTURE AND SHELF LIFE OF BLACK CHERRY TOMATOES (Solanum lycopersicum cv. OG)
}

\author{
NGAN HA HO THI ${ }^{1,2,3^{*}}$, THANH QUI TRAN ${ }^{3}$, TRI TIN NGUYEN ${ }^{3}$, THANH THU NGUYEN ${ }^{3}$, \\ TRONG SON NGUYEN ${ }^{3}$, HUYEN TRANG DUONG THI ${ }^{3}$ and MINH THUY NGUYEN ${ }^{3}$ \\ ${ }^{1}$ Faculty of Agriculture and Natural Resources, An Giang University, Vietnam \\ ${ }^{2}$ Vietnam National University Ho Chi Minh City, Vietnam \\ ${ }^{3}$ Department of Food Technology, College of Agriculture, Can Tho University, Vietnam \\ *E-mail: htnha@agu.edu.vn
}

Accepted 1 September 2020, Published online 25 October 2020

\begin{abstract}
The use of vacuum infiltration in the food industry has several advantages, such as improving the quality, eliminating chemical treatment requirements, stabilizing products, and retaining nutrients during storage and processing. This study was performed to optimize the vacuum level $(516-684 \mathrm{mmHg})$, treatment time $(10-20 \mathrm{~min})$, and calcium chloride $\left(\mathrm{CaCl}_{2}\right)$ concentration $(0.58$ $1.42 \%$ ) using the Response Surface Methodology (RSM). The firmness of black cherry tomatoes (Solanum lycopersicum $\mathrm{cv}$. OG) reached an optimum value $\left(1477.81 \mathrm{~g} / \mathrm{cm}^{2}\right)$ when fruits were treated at a vacuum level of $637 \mathrm{mmHg}$ with a concentration of $\mathrm{CaCl}_{2} 1.09 \%$ for $17 \mathrm{~min}$. Meanwhile, the firmness was $746 \mathrm{~g} / \mathrm{cm}^{2}$ for the control sample, which was dipped in $1.42 \% \mathrm{CaCl}_{2}$ solution for $20 \mathrm{~min}$ at the atmospheric condition. The scanning electron microscope (SEM) images of stomata of two samples with/without vacuum treatment were also significantly different. The sample after vacuum treatment at optimum parameters was put into PE and PP bags for storage at $10-12^{\circ} \mathrm{C}$. Vacuum-infiltrated tomatoes contained in PE and PP bags had a corresponding storage time of 30 and 28 days. The control samples were maintained for shorter periods, only 22 and 20 days, respectively.
\end{abstract}

Key words: Black cherry tomato, vacuum infiltration, calcium chloride, firmness, SEM image, shelf-life

\section{INTRODUCTION}

Tomato (Solanum lycopersicum L.) is a common vegetable that can either be used in fresh form or an ingredient in many processed products (Toor \& Savage, 2005). 'Black' or 'purple' is a name often applied to varieties exhibiting a purplish-brown color (Mes et al., 2008). In addition to the known bioactive compounds, purple tomatoes also contain anthocyanin (Li et al., 2011). Anthocyanin has been proven to be associated with many health benefits (Lila, 2004).

Tomatoes are easily perishable during harvesting, transportation, and storage (Pila et al., 2010). If proper post-harvest technology (fruit handling, packaging, and storage) is not available, tomatoes not only reduce their quality but also lose their weight significantly (Pila et al., 2010). Approximately $20-50 \%$ of fresh tomatoes were lost

\footnotetext{
* To whom correspondence should be addressed.
}

at harvest and post-harvest stages in tropical countries (Pila et al., 2010). Calcium has gained a lot of attention due to its high effectiveness in delaying the ripening and senescence as well as reducing physiological disorders and extending the storage time (Bhattarai \& Gautam, 2006). The ripening could be delayed when increasing calcium chloride $\left(\mathrm{CaCl}_{2}\right)$ concentration for tomato treatment (Senevirathna \& Daundasekera, 2010).

Vacuum impregnation is considered a treatment to incorporate functional components into the porous structure of fruit and vegetables, in which, the driving force of the mass transfer process is due to the pressure difference (Radziejewska-Kubzdela et al., 2014). The storage time of many types of fruit and vegetables such as apples (Scott \& Wills, 1979), avocados (Wills et al., 1988), strawberries (Ponappa et al., 1993), lemons (Valero et al., 1998), tomatoes (Senevirathna \& Daundasekera, 2010) and grapes (Mao et al., 2017) has been improved by the application of vacuum technique during the 
infiltration of fruits in preservative solutions. Many studies on vacuum infiltration showed the feasibility and validity of the combination of hydrodynamic mechanism and deformation-relaxation phenomena (Mao et al., 2017).

In the present study, the effect of vacuum level, treatment time, and $\mathrm{CaCl}_{2}$ concentration was investigated for a new cultivar of black cherry tomato 'cv. OG' in Vietnam. The quality of fruits (in polyethylene (PE) and polypropylene (PP) bags) was evaluated after infiltration and during storage at $10-12^{\circ} \mathrm{C}$.

\section{MATERIALS AND METHODS}

\section{Tomato fruits}

Black cherry tomato (cv. OG) seeds were provided by the F1508 seed store (Ho Chi Minh City, Vietnam) and grown in a garden house at Nam Long farm, Vinh Long province. Tomatoes were harvested 28 days after fruit formation. Fruits were packed into a perforated styrofoam box. They were transported to the Food Technology Laboratory of Can Tho University within $1 \mathrm{hr}$. Tomatoes were washed and then dipped into the water which was aerated with ozone for $15 \mathrm{~min}$ by a Z755 2-nozzle ozone generator, Vietnam (ozone-generating of $80.4 \mathrm{mg} / \mathrm{h}$ ). Fruits were drained and used for all experiments.

\section{Experimental design}

\section{Optimization of fruit treatment in calcium chloride solution by vacuum technique}

This experiment was optimized using the Response Surface Methodology (RSM) with a model of Central Composite Design (CCD). The experiment was designed with three factors (Table 1 ). The total run was 20 , including six replications at the center point. Each sample was $500 \mathrm{~g}$ of tomatoes and a ratio of raw material and $\mathrm{CaCl}_{2}$ solution was 1:1. The infiltration process was carried out in vacuum equipment (Rocker 400, Laftech, Australia). A control sample was also conducted by soaking tomatoes in a $1.42 \% \mathrm{CaCl}_{2}$ solution for 20 $\mathrm{min}$ at the atmospheric pressure. The firmness of tomatoes was measured. The SEM image was taken for the cross-section of fruit slices.

\section{Determination of shelf life of tomatoes treated in $\mathrm{CaCl}_{2}$ solution by vacuum infiltration method and contained in two types of bags}

After treatment in $\mathrm{CaCl}_{2}$ solution by vacuum technique with optimal parameters, the tomatoes were packed in PE and PP bags and stored in a refrigerator at $10-12^{\circ} \mathrm{C}$. Each sample was $1000 \mathrm{~g}$ of tomatoes. The bags had the same size of $20 \times 30 \times 0.015 \mathrm{~cm}$ and perforated proportion of $0.5 \%$ compared to their area. After every two days, the weight loss (\%), the content of bioactive compounds such as anthocyanin $(\mathrm{mgCE} / 100 \mathrm{~g})$, lycopene $(\mu \mathrm{g} / \mathrm{g})$, vitamin $\mathrm{C}(\mathrm{mg} / 100 \mathrm{~g})$, total phenolic content $(\mathrm{mgGAE} / 100 \mathrm{~g})$ with DPPH free radical scavenging activity (\%) and acceptability of consumers were evaluated.

\section{Analytical method}

\section{Scanning electron microscope (SEM) images}

SEM images were taken at Advanced Laboratory, Can Tho University, Vietnam. The tomatoes were cut horizontally at the middle into $1 \mathrm{~mm}$ thick slices and photographed with a scanning electron microscope (JEOL JSM-7600F, USA).

\section{Firmness of tomatoes}

The firmness of tomatoes was determined by Rheo Tex (SD 700, Sun Science Co. LTD, Japan). A $1 \mathrm{~cm}$ - diameter cylindrical probe with a flat end was used in this case. The force required to press vertically into the middle of fruits for a $4 \mathrm{~mm}$ distance was measured and expressed in $\mathrm{g} / \mathrm{cm}^{2}$.

Table 1. Experimental layout

\begin{tabular}{|c|c|c|c|c|c|c|c|}
\hline Run & $\begin{array}{c}\text { Vacuum } \\
\text { level }\left(\mathrm{X}_{1}\right) \\
(\mathrm{mmHg})\end{array}$ & $\begin{array}{l}\text { Treatment } \\
\text { time }\left(\mathrm{X}_{2}\right) \\
(\mathrm{min})\end{array}$ & $\begin{array}{c}\mathrm{CaCl}_{2} \\
\text { concentration } \\
\left(\mathrm{X}_{3}\right)(\%)\end{array}$ & Run & $\begin{array}{l}\text { Vacuum } \\
\text { level }\left(\mathrm{X}_{1}\right) \\
(\mathrm{mmHg})\end{array}$ & $\begin{array}{c}\text { Treatment } \\
\text { time }\left(X_{2}\right) \\
(\min )\end{array}$ & $\begin{array}{c}\mathrm{CaCl}_{2} \\
\text { concentration } \\
\left(\mathrm{X}_{3}\right)(\%)\end{array}$ \\
\hline 1 & 516 & 15 & 1 & 11 & 600 & 15 & 1 \\
\hline 2 & 550 & 12 & 0.75 & 12 & 600 & 15 & 1 \\
\hline 3 & 550 & 18 & 0.75 & 13 & 600 & 15 & 1 \\
\hline 4 & 550 & 12 & 1.25 & 14 & 600 & 20 & 1 \\
\hline 5 & 550 & 18 & 1.25 & 15 & 600 & 15 & 1.42 \\
\hline 6 & 600 & 15 & 0.58 & 16 & 650 & 12 & 0.75 \\
\hline 7 & 600 & 10 & 1 & 17 & 650 & 18 & 0.75 \\
\hline 8 & 600 & 15 & 1 & 18 & 650 & 12 & 1.25 \\
\hline 9 & 600 & 15 & 1 & 19 & 650 & 18 & 1.25 \\
\hline 10 & 600 & 15 & 1 & 20 & 684 & 15 & 1 \\
\hline
\end{tabular}




\section{Weight loss}

The weight loss (\%) of fruits during storage was calculated according to equation 1 , where $W_{o}$ is the weight of tomatoes at the beginning $(\mathrm{g}) ; W_{i}$ is the weight of tomatoes at various times during storage $(\mathrm{g})$.

$$
X(\%)=\frac{W_{o}-W_{i}}{W_{o}} \times 100
$$

\section{Anthocyanin content}

The anthocyanin content was determined by the $\mathrm{pH}$ differential method (Lee et al., 2005) with some modifications. Tomato puree $(5 \mathrm{~g})$ was filled to a volume of $50 \mathrm{~mL}$ with ethanol/water $(1 / 1)$ solvent containing $1 \% \mathrm{HCl}$ and extracted for 60 min. The mixture was then separated by a centrifuge at $7000 \times \mathrm{g}$ for $10 \mathrm{~min}$. The supernatant was diluted with two buffers of $\mathrm{pH} 1.0$ and 4.5 and read the absorbance at both 520 and $700 \mathrm{~nm}$ versus a blank of distilled water. The anthocyanin content was calculated as cyanidin-3-glucoside equivalent (equation 2), where $A$ is $\left(\mathrm{A}_{520 \mathrm{~nm}}-\mathrm{A}_{700 \mathrm{~nm}}\right) \mathrm{pH} 1.0-$ $\left(\mathrm{A}_{520 \mathrm{~nm}}-\mathrm{A}_{700 \mathrm{~nm}}\right) \mathrm{pH} 4.5, M$ is $449.2 \mathrm{~g} / \mathrm{mol}$ for cyanidin-3-glucoside, $k$ is the dilution factor, $l$ is the pathlength $(\mathrm{cm}), \varepsilon$ is 26900 - molar extinction coefficient for cyanidin-3-glucoside $\left(\mathrm{L} \times \mathrm{mol}^{-1} \times \mathrm{cm}^{-1}\right)$, $V$ is the volume of extract $(\mathrm{mL}), m$ is the weight of sample (g).

$$
\underset{(\mathrm{mgCE} / 100 \mathrm{~g})}{\text { Anthocyanin }}=\frac{A \times M \times k \times V}{m \times \varepsilon \times l} \times 100 \times 1000
$$

\section{Lycopene content}

The lycopene content was determined by the low volume hexane extraction method (Davis et al., 2003; Fish et al., 2002). Tomato puree (0.6 g) was mixed with $5 \mathrm{~mL}$ of acetone containing $0.05 \%$ butylated hydroxytoluene, $5 \mathrm{~mL}$ of $95 \%$ ethanol, $10 \mathrm{~mL}$ of hexane and extracted for $15 \mathrm{~min}$ on a shaker at a speed of $180 \mathrm{rpm}$. The mixture was then added to $3 \mathrm{~mL}$ of deionized water and shook for another $5 \mathrm{~min}$. The vial was left for $5 \mathrm{~min}$. The absorbance of the supernatant layer was read at $503 \mathrm{~nm}$ against a blank of hexane. The lycopene content was determined using equation 3 , where $A_{503}$ is the absorbance of extract at $503 \mathrm{~nm}, m$ is the weight of sample $(\mathrm{g})$.

$$
\text { Lycopene }(\mu \mathrm{g} / \mathrm{g})=\frac{A_{503} \times 31.2}{m}
$$

\section{Vitamin C content}

The vitamin $\mathrm{C}$ content was determined by the titration method (Lam et al., 2004). Tomato puree
(10 g) was filled to a volume of $100 \mathrm{~mL}$ with $5 \%$ $\mathrm{HCl}$ solution and filtered through a filter paper. The filtrate $(10 \mathrm{~mL})$ was added 5 drops of the $1 \%$ starch solution and titrated with the $0.001 \mathrm{~N} \mathrm{KIO}_{3} / \mathrm{KI}$ solution until the blue-black color appears. For the control, the sample extract was replaced by the $1 \%$ $\mathrm{HCl}$ solution. The vitamin $\mathrm{C}$ content was calculated using equation 4 , where $a$ and $b$ is the volume of $0.001 \mathrm{~N} \mathrm{KIO}_{3} / \mathrm{KI}$ solution used for titration the extract and the control, respectively $(\mathrm{mL}), 100$ is the volume of extract $(\mathrm{mL}), 0.088$ is the weight of ascorbic acid corresponds to $1 \mathrm{~mL}$ of $0.001 \mathrm{~N} \mathrm{KIO}_{3} /$ KI solution (mg), $m$ is the weight of sample ( $\mathrm{g}$ ).

$\underset{(\mathrm{mg} / 100 \mathrm{~g})}{\operatorname{Vitamin} C}=\frac{(a-b) \times 0.088 \times 100}{10} \times \frac{100}{m}$

\section{Total phenolic content}

The total phenolic content was determined using Folin-Ciocalteu reagent (Teixeira et al., 2013) with some modifications. Tomato puree $(5 \mathrm{~g})$ was filled to a volume of $50 \mathrm{~mL}$ with $95 \%$ ethanol and extracted for $60 \mathrm{~min}$. The mixture was then separated by a centrifuge at $7000 \times \mathrm{g}$ for $10 \mathrm{~min}$. The supernatant $(0.2 \mathrm{~mL})$ was added $1.0 \mathrm{~mL}$ of $10 \%$ Folin-Ciocalteu reagent, left for $5 \mathrm{~min}$ and then added $1.2 \mathrm{~mL}$ of $5 \% \mathrm{Na}_{2} \mathrm{CO}_{3}$ solution. After $2 \mathrm{hr}$, the absorbance was recorded at $750 \mathrm{~nm}$. The total phenolic content was calculated as gallic acid equivalent (equation 5), where $C$ is the content of gallic acid derived from the standard curve $(\mathrm{mg} / \mathrm{mL})$, $V$ is the volume of extract $(\mathrm{mL}), m$ is the weight of sample $(\mathrm{g}), k$ is the dilution factor.

Phenolic $(\mathrm{mgGAE} / 100 \mathrm{~g})=\frac{\mathrm{C} \times \mathrm{V}}{\mathrm{m}} \times \mathrm{k} \times 100$

\section{Antioxidant activity}

Antioxidant activity was determined using the DPPH assay (Teixeira et al., 2013) with some modifications. Tomato puree $(5 \mathrm{~g})$ was filled to a volume of $50 \mathrm{~mL}$ with $95 \%$ ethanol and extracted for $60 \mathrm{~min}$. The mixture was then separated by a centrifuge at $7000 \times \mathrm{g}$ for $10 \mathrm{~min}$. The supernatant $(0.1 \mathrm{~mL})$ was added $2 \mathrm{~mL}$ of DPPH solution $(0.21$ $\mathrm{mM}$ in $95 \%$ ethanol). For the control, the sample extract was replaced with $95 \%$ ethanol. The mixture was kept for $1 \mathrm{hr}$ before absorbance reading at $517 \mathrm{~nm}$. The percentage of DPPH free radical scavenging was calculated by equation 6 , where $A_{\text {control }}$ is the absorbance of control, $A_{\text {sample }}$ is the absorbance of sample.

$\operatorname{DPPH}(\%)=\frac{A_{\text {control }}-A_{\text {sample }}}{A_{\text {control }}} \times 100$ 


\section{Consumer acceptability}

Acceptability of consumers was estimated using the odds ratio for the relationship between two binary ("yes or no") variables (Bland \& Altman, 2000). Twenty participants were asked to assess the acceptability of tomatoes [Is this tomato acceptable? Yes $\{1$ score $\}$ No $\{0$ score $\}]$ (Garcia et al., 2009).

\section{Data analysis}

Data analyses was carried out using STATGRAPHICS Centurion XV (U.S.A.). The significance/non-significance of results was determined using the two-way ANOVA and Duncan test. The logistic regression model was applied to analyze the acceptability of consumers for tomatoes by storage time. The correlation model between acceptability and storage time was established (equation 7).

Acceptability $=\exp (\eta) /(1+\exp (\eta))$

\section{RESULTS AND DISCUSSION}

Optimization of $\mathrm{CaCl}_{2}$ treatment of black cherry tomatoes by vacuum infiltration method

The results in Table 2 showed that the effect of individual independent variables $\left(\mathrm{X}_{1}, \mathrm{X}_{2}, \mathrm{X}_{3}\right)$ and quadratic values $\left(\mathrm{X}_{1}{ }^{2}, \mathrm{X}_{2}{ }^{2}, \mathrm{X}_{3}{ }^{2}\right)$ were significant $(p<0.05)$ but the effect of interactivity $\left(\mathrm{X}_{1} \mathrm{X}_{2}\right.$, $\left.\mathrm{X}_{1} \mathrm{X}_{3}, \mathrm{X}_{2} \mathrm{X}_{3}\right)$ was not significant $(p<0.05)$ when participated in the model.

The relationship between firmness and independent variables was established (equation 8). The correlation between the estimated and the experimental firmness of tomatoes was satisfactory (Figure 1).

Firmness $\left(\mathrm{g} / \mathrm{cm}^{2}\right)=$

$-9929.64+28.5859 X_{1}+150.182 X_{2}+1875.15 X_{3}$

$-0.0234796 * \mathrm{X}_{1}^{2}+0.0775 \mathrm{X}_{1} \mathrm{X}_{2}+0.01 \mathrm{X}_{1} \mathrm{X}_{3}$

$-5.79997 \mathrm{X}_{2}^{2}-2.16667 \mathrm{X}_{2} \mathrm{X}_{3}-842.813 \mathrm{X}_{3}^{2}$

Table 2. Analysis of variance for firmness

\begin{tabular}{lcccc}
\hline Source & Sum of Squares & Df & F-Ratio & $p$-value \\
\hline $\mathrm{X}_{1}:$ Vacuum level & 85464.1 & 1 & 336.47 & 0.0000 \\
$\mathrm{X}_{2}:$ Treatment time & 51352.5 & 1 & 202.18 & 0.0000 \\
$\mathrm{X}_{3}: \mathrm{CaCl}_{2}$ concentration & 22665.7 & 1 & 89.24 & 0.0002 \\
$\mathrm{X}_{1}{ }^{2}$ & 49529.8 & 1 & 195.00 & 0.0000 \\
$\mathrm{X}_{1} \mathrm{X}_{2}$ & 1081.13 & 1 & 4.26 & 0.0941 \\
$\mathrm{X}_{1} \mathrm{X}_{3}$ & 0.125 & 1 & 0.00 & 0.9832 \\
$\mathrm{X}_{2}{ }^{2}$ & 38175.8 & 1 & 150.30 & 0.0001 \\
$\mathrm{X}_{2} \mathrm{X}_{3}$ & 21.125 & 1 & 0.08 & 0.7846 \\
$\mathrm{X}_{3}{ }^{2}$ & 39886.5 & 1 & 157.03 & 0.0001 \\
\hline
\end{tabular}

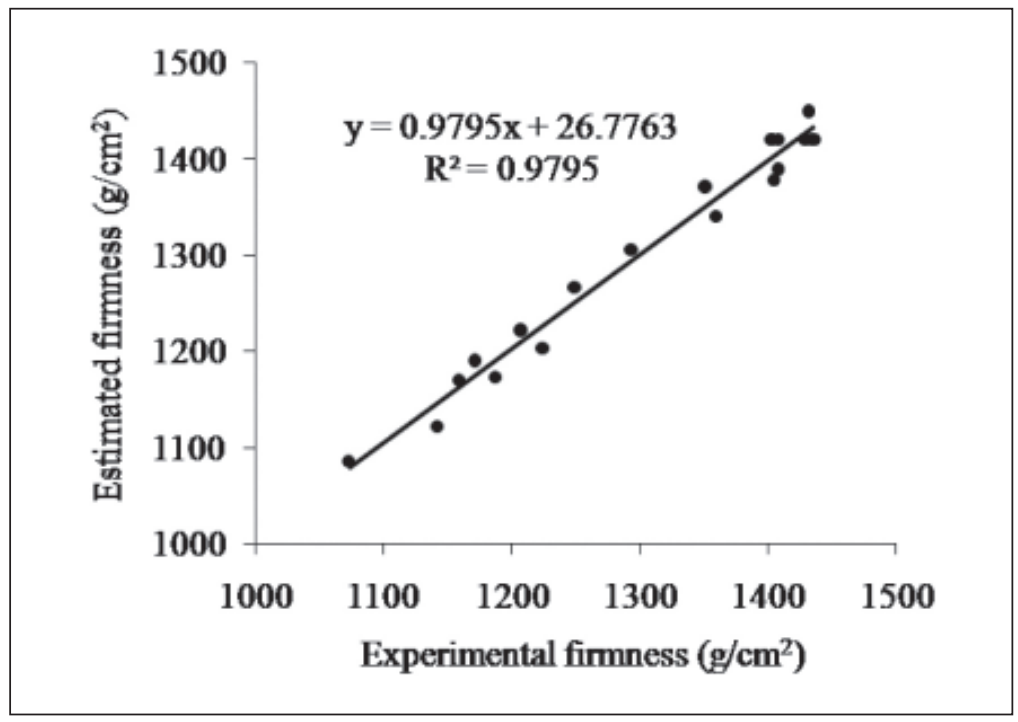

Fig. 1. Correlation between the experimentally determined values and the estimated values for the firmness of tomatoes. 
Response surface graphs showed the interaction between vacuum level, treatment time, and $\mathrm{CaCl}_{2}$ concentration to the firmness of black cherry tomatoes were presented in Figure 2. As the vacuum level, treatment time, and $\mathrm{CaCl}_{2}$ concentration increased, the firmness of fruits also increased to $1477.81 \mathrm{~g} / \mathrm{cm}^{2}$, which tended not to increase continually. The model predicted that firmness reached the optimum value when tomatoes were infiltrated in a $1.09 \% \mathrm{CaCl}_{2}$ solution for $17 \mathrm{~min}$ at a vacuum level of $637 \mathrm{mmHg}$. As the content of calcium in tomato pericarp increases, it may strengthen cation bridges between uronic acid groups to create the stability of cell walls (Senevirathna \& Daundasekera, 2010). Vacuum infiltration technology is used to replace the pressure infusion process, which helps to increase calcium content quickly contributing to improve fruit firmness (Senevirathna \& Daundasekera, 2010).

The morphological features of the stomata of tomatoes based on their SEM images (Figure 3) demonstrated the effect of vacuum treatment on the texture of fruits. During vacuum treatment, gases in the food matrix expand and escape outside and after restoring atmospheric pressure, the pressure difference causes the liquid to penetrate the pores until the pressure reaches an inside and outside balance (Saurel, 2002).

\section{Determination the shelf life of tomatoes treated in $\mathrm{CaCl}_{2}$ solution at vacuum pressure and contained in two types of bag}

The infiltration of tomatoes in $\mathrm{CaCl}_{2}$ solution by vacuum method increased the firmness of fruit, therefore, the storage time at the temperature of $10-12^{\circ} \mathrm{C}$ was longer (34 days for the vacuum sample and 28 days for the control set in PE bags), compared to 30 days and 24 days in PP bags, respectively. During these periods, fruits were still undamaged. Calcium is the constituent of middle lamellae and the weakening of middle lamellae resulted in the softening of fruits during ripening (Bhattarai \& Gautam, 2006). Calcium acts as a bridge between polygalacturonic acid molecules that strengthen the membrane, thereby reducing the rate of evaporation and respiration leading to slowing down the senescence (Bhattarai \& Gautam, 2006). PE bags had better air permeability than PP bags (Dong, 2005), which helped to reduce the damage of fruits due to anaerobic respiration.

\section{Weight loss}

A progressive increase in weight loss was observed in all samples during storage. Evaporation and respiration are the main causes of the weight loss of fruit and vegetables, in which, the diffusion of vapor-phase is due to the difference in water vapor

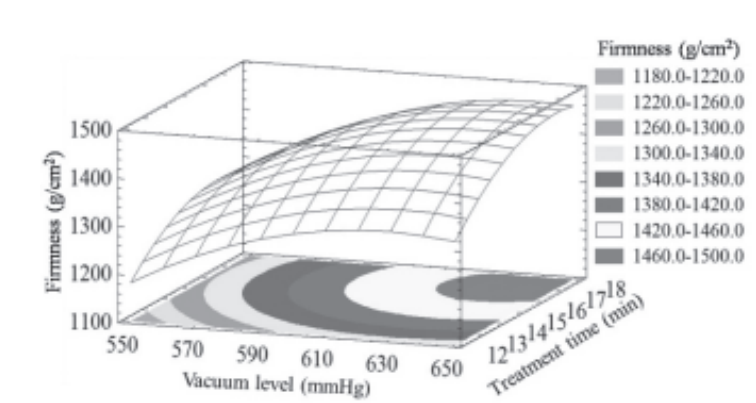

a.

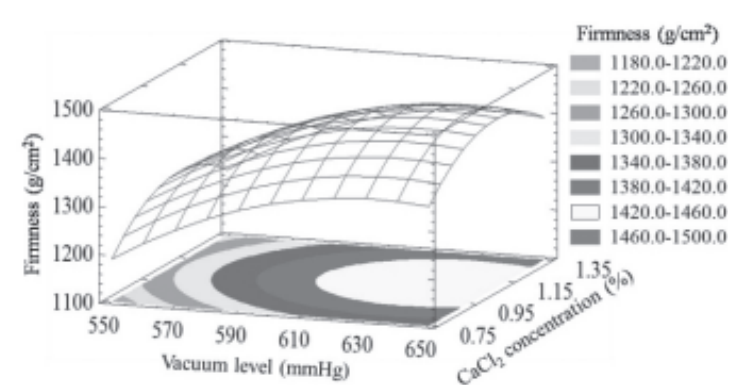

b.

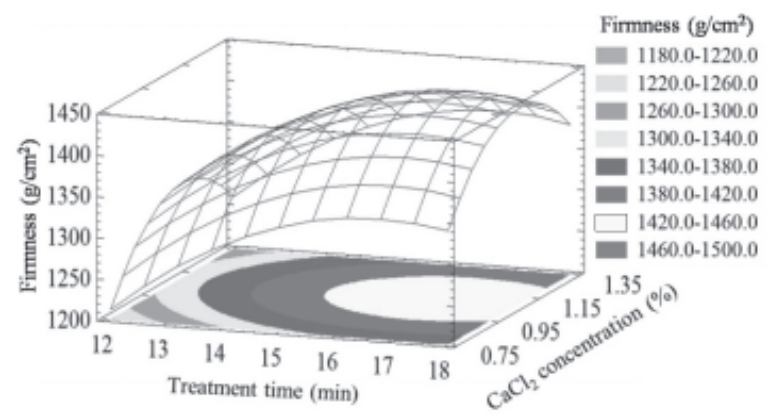

c.

Fig. 2. The response surface and contour plots of firmness as the function of (a)Vacuum level and treatment time; (b) Vacuum level and $\mathrm{CaCl}_{2}$ concentration; (c) Treatment time and $\mathrm{CaCl}_{2}$ concentration. 


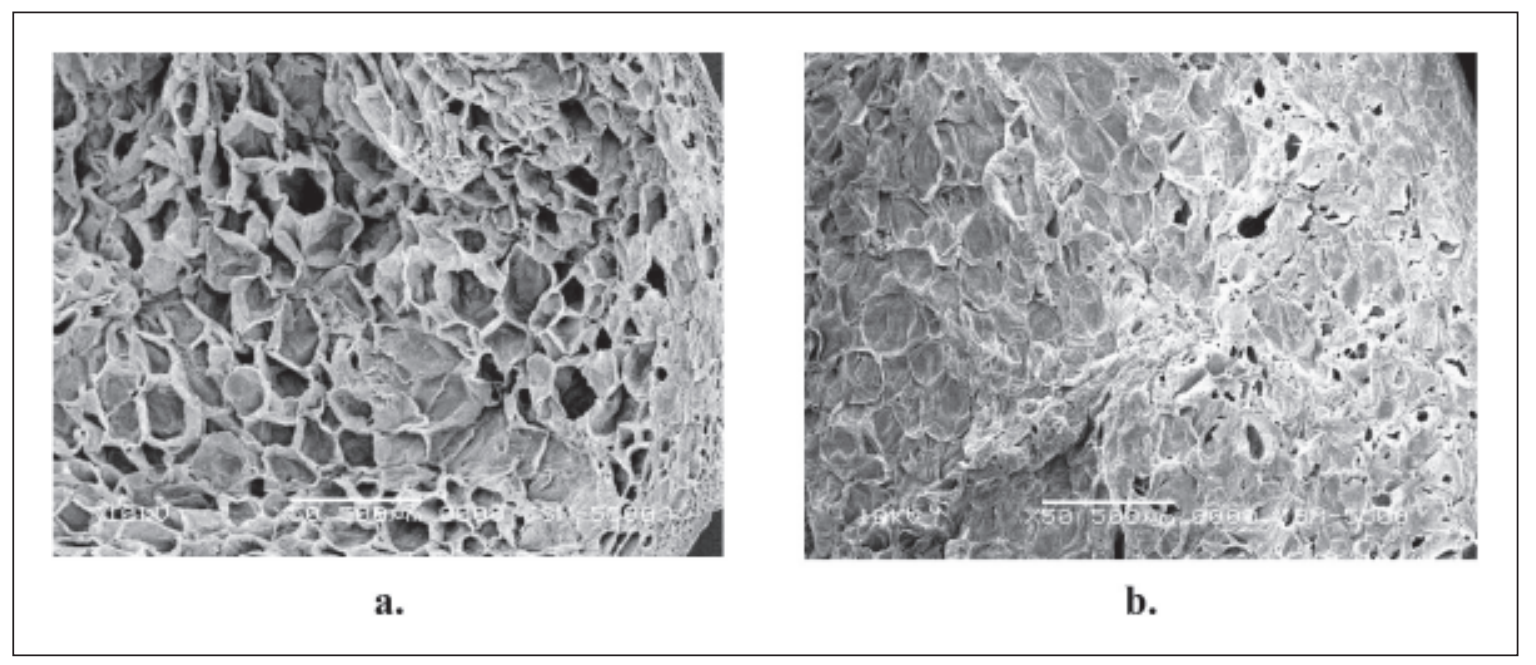

Fig. 3. SEM images of tomato fruits infiltrated in $1.09 \% \mathrm{CaCl}_{2}$ solution for 17 min (a) At atmospheric pressure; (b) At a vacuum level of $637 \mathrm{mmHg}$.

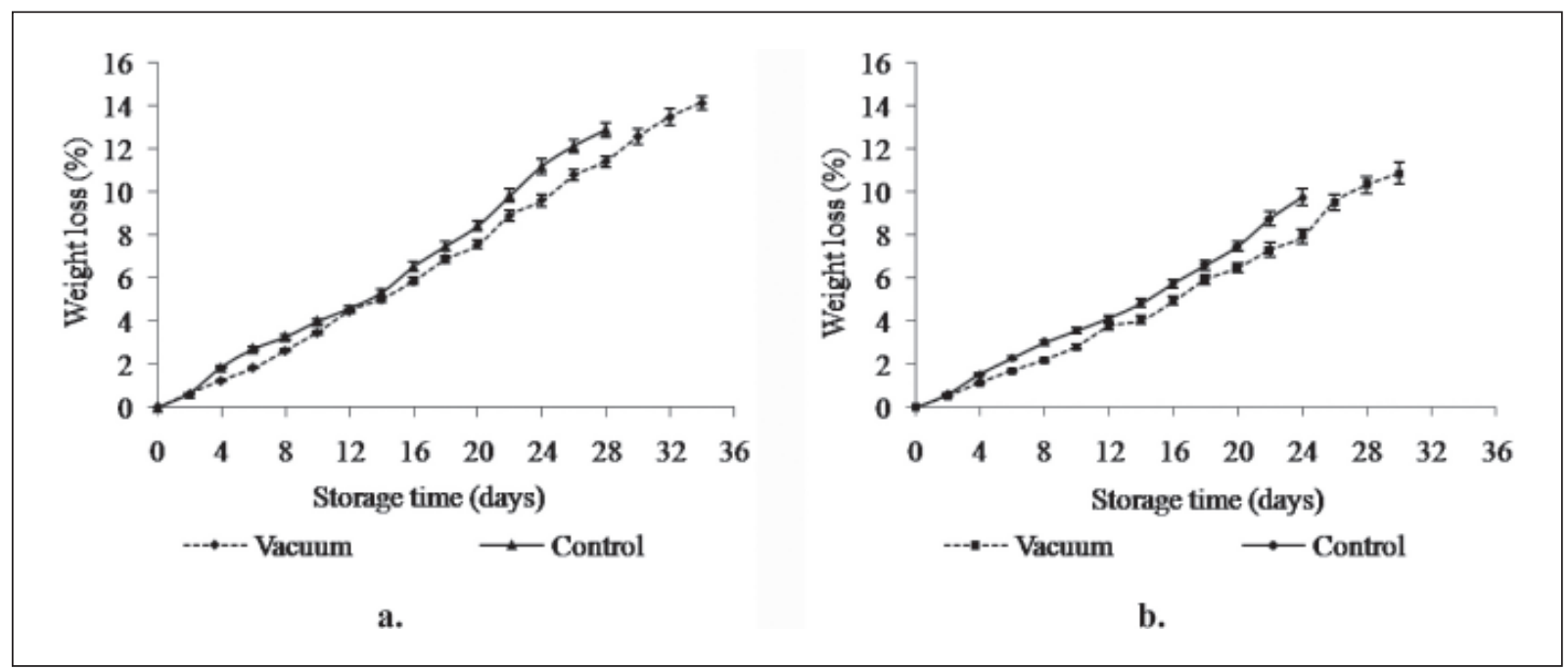

Fig. 4. Weight loss of black cherry tomatoes with/without vacuum treatment by storage time (a) PE bags; (b) PP bags.

pressure between material surface and environment (Pila et al., 2010). Fruits that were vacuum-treated in $\mathrm{PE}$ and PP bags had a corresponding weight loss of $9.62 \%$ and $7.94 \%$ after 24 storage days. These values for control samples were higher with $11.19 \%$ and $9.76 \%$, respectively (Figure 4). Pila et al. (2010) reported that calcium enhances the structure of the membrane, thereby reducing the loss of protein and phospholipid components.

\section{Vitamin C content}

The vitamin $\mathrm{C}$ content (Figure 5) increased drastically in the early storage period. Tomato belongs to the group of climacteric fruits, therefore, after picking from the plant, the fruit continues to metabolize and ripen completely (Toor \& Savage, 2006). The vitamin $C$ content of fruits with vacuum treatment contained in PE and PP bags reached a maximum of $76.54 \mathrm{mg} / 100 \mathrm{~g}$ and $74.99 \mathrm{mg} / 100 \mathrm{~g}$, which was higher than the control sample $(73.85$ $\mathrm{mg} / 100 \mathrm{~g}$ in PE bags and $72.09 \mathrm{mg} / 100 \mathrm{~g}$ in PP bags). However, in the later stage of storage, the vitamin $\mathrm{C}$ content tended to decrease due to the ripening process of fruits stopped. In another study, where tomatoes were stored at $4{ }^{\circ} \mathrm{C}$, Galani et al. (2017) also showed a $71.8 \%$ decrease in vitamin $\mathrm{C}$ content after 14 days. During storage at low temperature, the fruits synthesize vitamin $\mathrm{C}$ as a response to stress, after that, oxidation by enzymes leads to the losses of vitamin C (Galani et al., 2017).

\section{Lycopene content}

The lycopene content was observed to increase significantly during storage (Figure 6). The ripening of tomato fruits retarded by the vacuum technique used for treatment in $\mathrm{CaCl}_{2}$ solution, the lycopene 


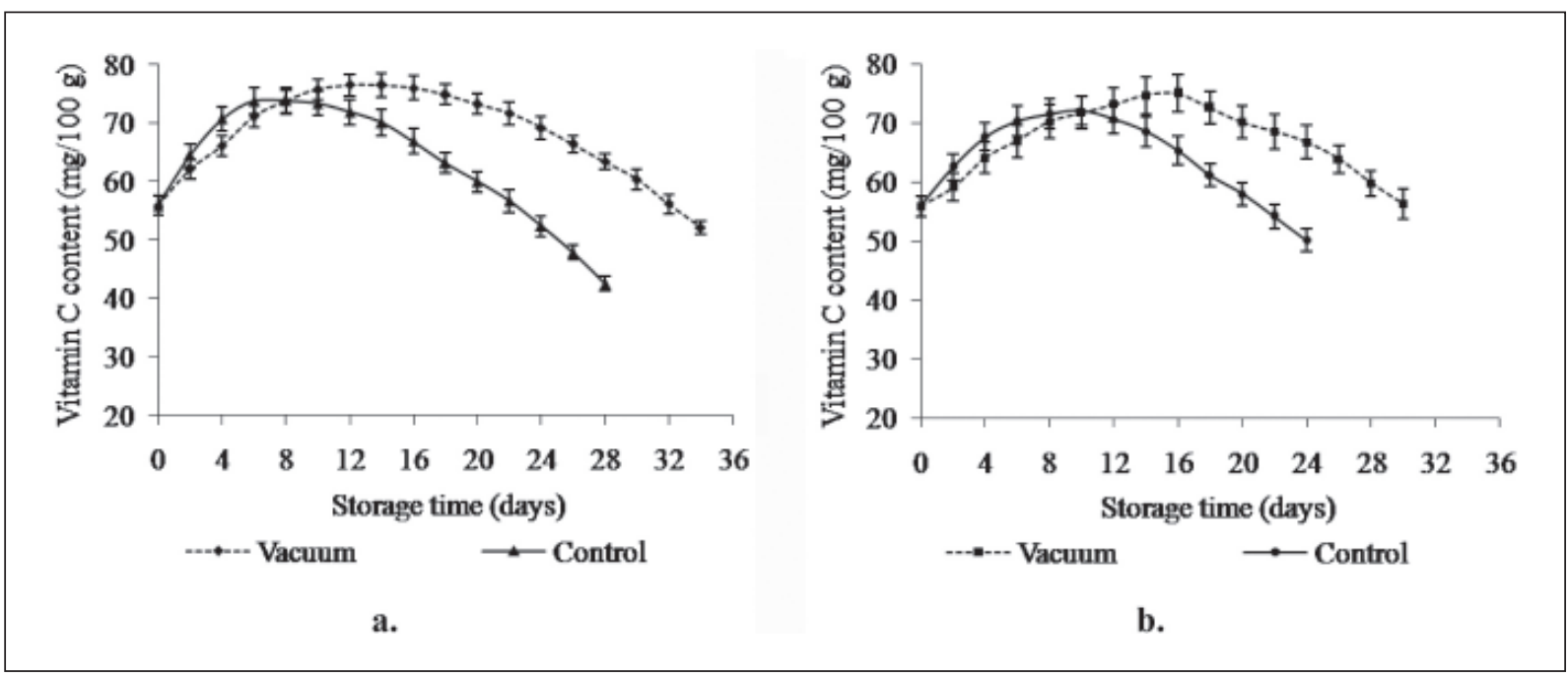

Fig. 5. Vitamin C content of black cherry tomatoes with/without vacuum treatment by storage time (a) PE bags; (b) PP bags.

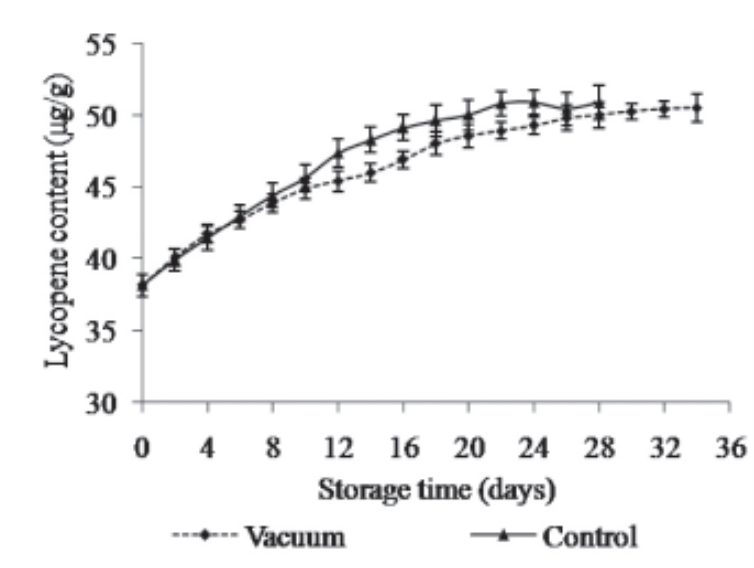

a.

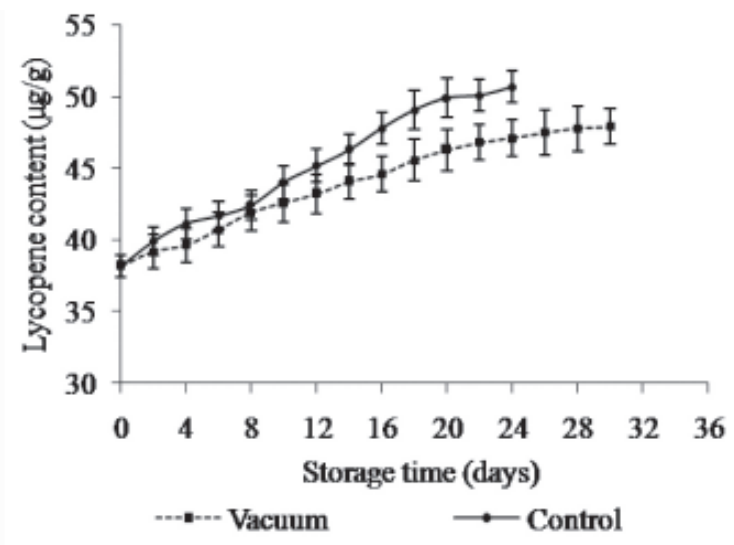

b.

Fig. 6. Lycopene content of black cherry tomatoes with/without vacuum treatment by storage time (a) PE bags; (b) PP bags.

content of treated and control samples was 48.57 and $50.01 \mu \mathrm{g} / \mathrm{g}$, respectively, after 20 days of storage in $\mathrm{PE}$ bags in comparison to the initial content $38.17 \mu \mathrm{g} / \mathrm{g}$. The lycopene accumulation during ripening leads to an increase in the redness of tomatoes (Toor \& Savage, 2006).

\section{Anthocyanin content}

Unlike lycopene, the anthocyanin content did not change significantly during storage (Figure 7) because anthocyanins were not synthesized continually after harvest. For fruits with infiltration in $\mathrm{CaCl}_{2}$ solution by vacuum method, the anthocyanin content decreased more slowly than the control set $\left(4.21 \mathrm{mgCE} / 100 \mathrm{~g}\right.$ on the $34^{\text {th }}$ day compared to $4.22 \mathrm{mgCE} / 100 \mathrm{~g}$ on the $28^{\text {th }}$ day in PE bags) from the initial value of $4.37 \mathrm{mgCE} / 100 \mathrm{~g}$.
Enzymes such as peroxidases, glycosidases, and polyphenoloxidases may have caused anthocyanin degradation during storage (Galani et al., 2017).

\section{Total phenolic content}

The total phenolic content of black cherry tomatoes tended to decrease during storage (Figure 8) with the highest loss recorded in fruits that vacuum treated and contained in $\mathrm{PE}$ bag (from $43.13 \mathrm{mgGAE} / 100 \mathrm{~g}$ to $33.77 \mathrm{mgGAE} / 100 \mathrm{~g}$ after 34 days). These results were similar to the previous study (Galani et al., 2017), a decrease in total phenolic concentration was observed during tomatoes storage at $4^{\circ} \mathrm{C}$ for 15 days and the degradation of phenolic compounds may be due to the catalytic activity of polyphenol oxidases. 


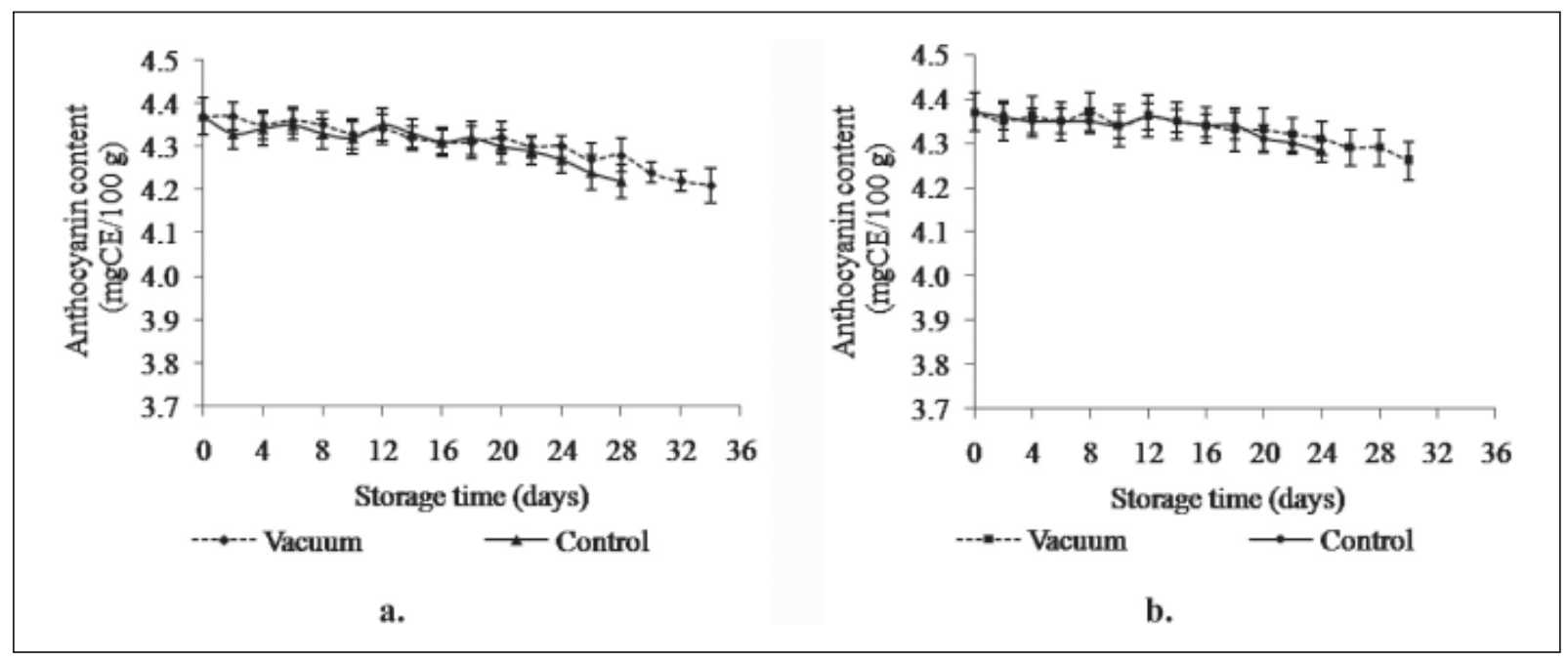

Fig. 7. Anthocyanin content of black cherry tomatoes with/without vacuum treatment by storage time (a) PE bags; (b) PP bags.

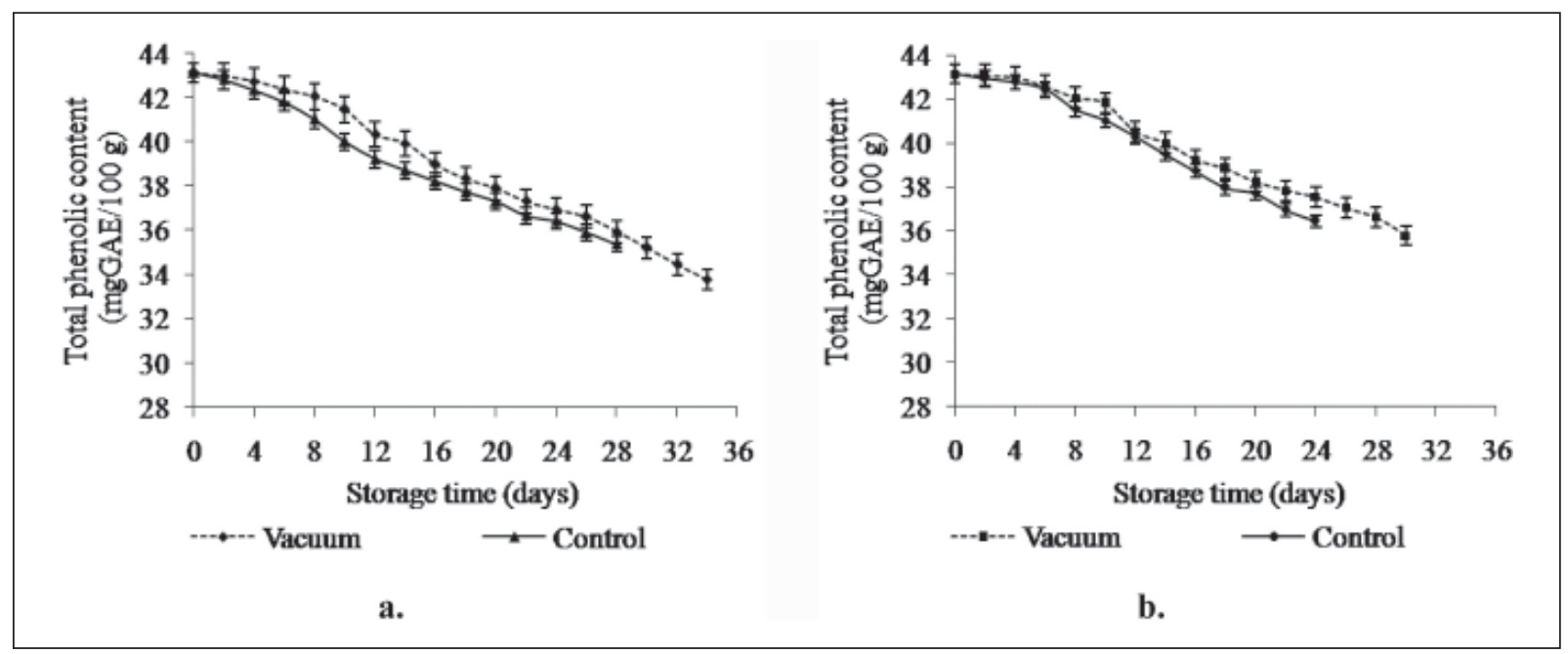

Fig. 8. Total phenolic content of black cherry tomatoes with/without vacuum treatment by storage time (a) PE bags; (b) PP bags.

\section{DPPH free radical scavenging activity}

Antioxidant activity of tomatoes was evaluated by the DPPH scavenging assay which tended to increase in the first days of storage and then dropped (Figure 9). Decrease of antioxidant activity during fruit storage may de due to the loss of vitamin C, anthocyanin, and phenolic compounds. Galani et al. (2017) also found a drastic decrease in antioxidant activity after storage tomatoes at $4^{\circ} \mathrm{C}$ for 15 days. However, the DPPH free radical scavenging of the vacuum treated fruits changed more slowly than the control sample.

\section{The acceptability of consumers during storage}

Results from the logistic regression model in Figure 10 showed that the acceptability of black cherry tomatoes maintained at high levels (>80\%) for vacuum-treated samples when stored in PE and
PP bags for 30 and 28 days, respectively. Meanwhile, the shelf-life of control samples was just only 22 and 20 days, respectively in PE and PP bags.

Results from Analysis of Deviance Table represented $p$-value for the model less than 0.05 , it could be concluded that there was a statistically significant relationship between variables (the confidence level of 95\%).

\section{CONCLUSION}

Implementing the pre-treatment process of black cherry tomatoes at the vacuum level of $637 \mathrm{mmHg}$, the treatment time of $17 \mathrm{~min}$, and the $\mathrm{CaCl}_{2}$ concentration of $1.09 \%$ that helped to achieve the good texture. The quality of fruits, treated with these 


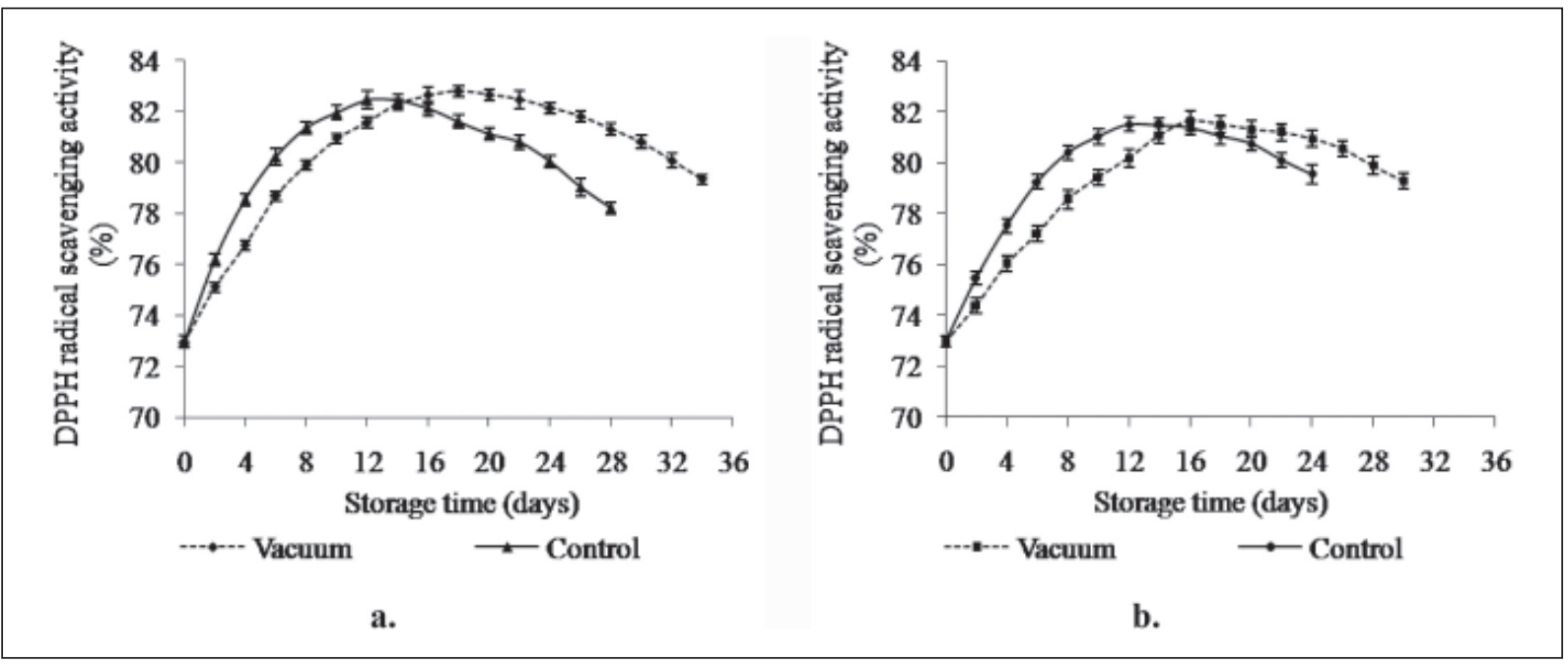

Fig. 9. DPPH free radical scavenging activity of black cherry tomatoes with/without vacuum treatment by storage time (a) PE bags (b) PP bags.

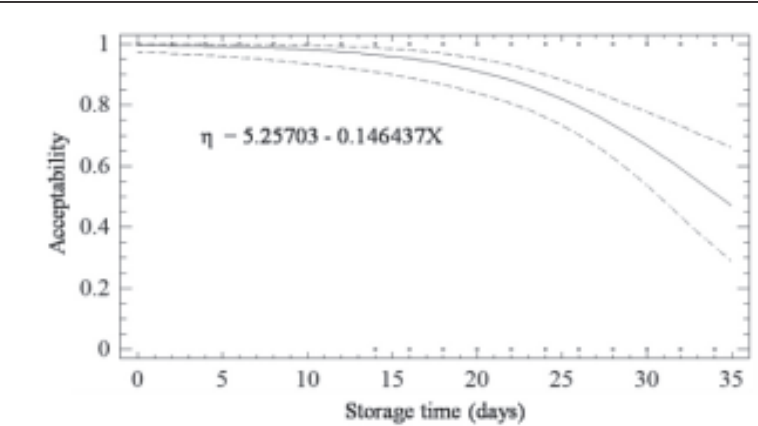

a.

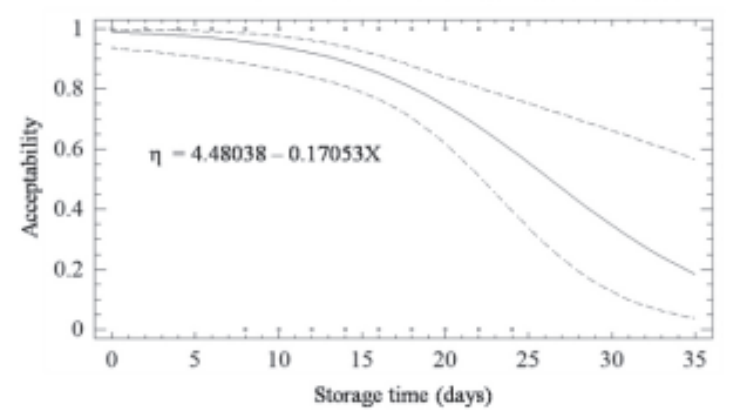

c.

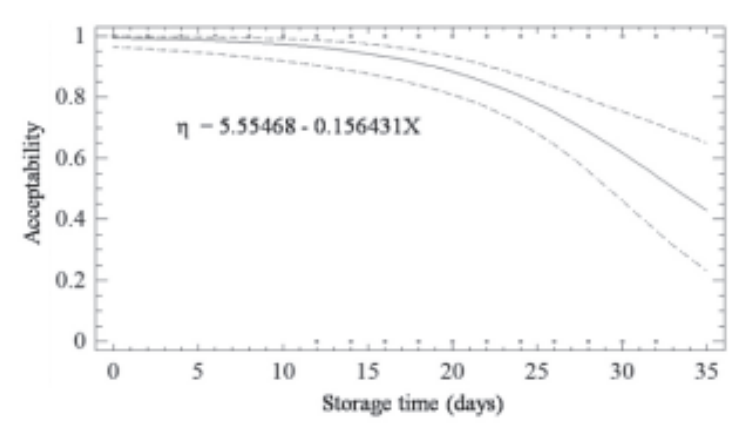

b.

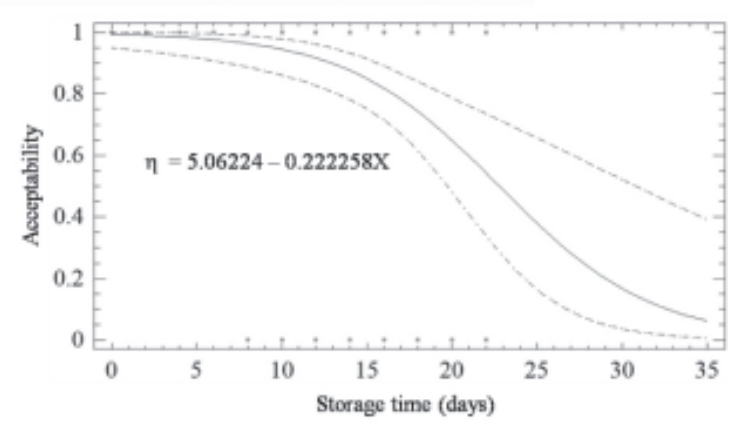

d.

Fig. 10. Acceptability of black cherry tomatoes (a) Vacuum-treated sample in PE bag; (b) Vacuum-treated sample in PP bag; (c) Control sample in PE bag; (d) Control sample in PP bag.

Note: The band inside the two dashed lines is the $95 \%$ point-wise confidence interval; the solid line is a forecast.

optimal parameters changed more slowly during storage than the control samples in both PE and PP bags. Compared to the control samples (only 22 and 20 days stored in PE and PP bags, respectively), black cherry tomatoes that were treated in $\mathrm{CaCl}_{2}$ solution by vacuum infiltration method and contained in PE and PP bags, then stored at $10-12^{\circ} \mathrm{C}$ had longer shelf life (30 and 28 days, respectively) and high acceptance to consumers. The vacuum technology was applied for black cherry tomato (Solanum lycopersicum cv. OG) treatment in $\mathrm{CaCl}_{2}$ solution proved to increase the firmness and prolonged the storage time of fruits compared to the control samples. 


\section{ACKNOWLEDGMENTS}

We would like to thank MT's Team of College of Agriculture, Can Tho University, Vietnam for supporting the implementation of experiments during this study.

\section{REFERENCES}

Bhattarai, D.R. \& Gautam, D.M. 2006. Effect of harvesting method and calcium on post harvest physiology of tomato. Nepal Agriculture Research Journal, 7: 37-41.

Bland, J.M. \& Altman, D.G. 2000. The odds ratio. British Medical Journal, 320(7247): 1468.

Davis, A.R., Fish, W.W. \& Perkins-Veazie, P. 2003. A rapid spectrophotometric method for analyzing lycopene content in tomato and tomato products. Postharvest Biology and Technology, 28: 425-430.

Dong, T.A.D. 2005. Food packaging techniques. Ho Chi Minh City National University Publishing. $270 \mathrm{pp}$.

Fish, W.W., Perkins-Veazie, P. \& Collins, J.K. 2002. A quantitative assay for lycopene that utilizes reduced volumes of organic solvents. Journal of Food Composition and Analysis, 15: 309317.

Galani, J.H., Patel, J.S., Patel, N.J. \& Talati, J.G. 2017. Storage of fruits and vegetables in refrigerator increases their phenolic acids but decreases the total phenolics, anthocyanins and vitamin $\mathrm{C}$ with subsequent loss of their antioxidant capacity. Antioxidants, 6(3): 59.

Garcia, K., Sriwattana, S., No, H.K., Corredor, J.A.H. \& Prinyawiwatkul, W. 2009. Sensory optimization of a mayonnaisetype spread made with rice bran oil and soy protein. Journal of Food Science, 74(6): S248-S254.

Lee, J., Durst, R.W. \& Wrolstad, R.E. 2005. Determination of total monomeric anthocyanin pigment content of fruit juices, beverages, natural colorants, and wines by the $\mathrm{pH}$ differential method: collaborative study. Journal of AOAC International, 88(5): 12691278.

Li, H., Deng, Z., Liu, R., Young, J.C., Zhu, H., Loewen, S. \&Tsao, R. 2011. Characterization of phytochemicals and antioxidant activities of a purple tomato (Solanum lycopersicum L.). Journal of Agricultural and Food Chemistry, 59(21): 11803-11811.

Lila, M.A. 2004. Anthocyanins and human health: an in vitro investigative approach. Journal of Biomedicine and Biotechnology, 2004(5): 306313.
Mao, J., Zhang, L., Chen, F., Lai, S., Yang, B. \& Yang, H. 2017. Effect of vacuum impregnation combined with calcium lactate on the firmness and polysaccharide morphology of Kyoho grapes (Vitis vinifera $\times$ V. labrusca). Food and Bioprocess Technology, 10(4): 699-709.

Mes, P.J., Boches, P., Myers, J.R. \& Durst, R. 2008. Characterization of tomatoes expressing anthocyanin in the fruit. Journal of the American Society for Horticultural Science, 133(2): 262-269.

Pila, N., Gol, N.B. \& Rao, T.R. 2010. Effect of post harvest treatments on physicochemical characteristics and shelf life of tomato (Lycopersicon esculentum Mill.) fruits during storage. American-Eurasian Agricultural \& Environmental Sciences, 9(5): 470-479.

Ponappa, T., Scheerens, J.C. \& Miller, A.R. 1993. Vacuum infiltration of polyamines increases firmness of strawberry slices under various storage conditions. Journal of Food Science, 58(2): 361-364.

Radziejewska-Kubzdela, E., Biegañska-Marecik, R. \& Kidoñ, M. 2014. Applicability of vacuum impregnation to modify physico-chemical, sensory and nutritive characteristics of plant origin products - a review. International Journal of Molecular Sciences, 15(9): 1657716610.

Saurel, R. 2002. The use of vacuum technology to improve processed fruit and vegetables, in "Fruit and Vegetable Processing". Woodhead Publishing Limited, Abington Hall, Abington Cambridge CB1 6AH, England. 401 pp.

Scott, K.J. \& Wills, R.B.H. 1979. Effects of vacuum and pressure infiltration of calcium chloride and storage temperature on the incidence of bitter pit and low temperature breakdown of apples. Australian Journal of Agricultural Research, 30(5): 917-928.

Senevirathna, P.A.W.A.N.K. \& Daundasekera, W.A.M. 2010. Effect of postharvest calcium chloride vacuum infiltration on the shelf life and quality of tomato (cv. 'Thilina'). Ceylon Journal of Science (Biological Sciences), 39(1): 35-44.

Teixeira, B., Marques, A., Ramos, C., Serrano, C., Matos, O., Neng, N.R., Nogueira, J.M.F, Saraiva, J.A. \& Nunes, M.L. 2013. Chemical composition and bioactivity of different oregano (Origanum vulgare) extracts and essential oil. Journal of the Science of Food and Agriculture, 93(11): 2707-2714.

Toor, R.K. \& Savage, G.P. 2005. Antioxidant activity in different fractions of tomatoes. Food Research International, 38(5): 487-494. 
Toor, R.K. \& Savage, G.P. 2006. Changes in major antioxidant components of tomatoes during post-harvest storage. Food Chemistry, 99(4): 724-727.

Tran, B.L., Ton, N.M.N. \& Dinh, T.N.T. 2004. Food biochemical experiment. Ho Chi Minh City National University Publishing. 83 pp.

Valero, D., Martínez-Romero, D., Serrano, M. \& Riquelme, F. 1998. Influence of postharvest treatment with putrescine and calcium on endogenous polyamines, firmness, and abscisic acid in lemon (Citrus lemon L. Burm cv. Verna). Journal of Agricultural and Food Chemistry, 46(6): 2102-2109.
Wills, R.B.H., Sirivatanapa, S. \& Somjate, S. 1988. Evaluation of postharvest infiltration of calcium to delay the ripening of avocados. Australian Journal of Experimental Agriculture, 28(6): 801-804. 
